\title{
Forest Recovering and Soil Respiration Rate
}

\author{
Mande, Kato Hosea ${ }^{1}$, Abdullah, Ahmad. Makmom².,Nuruddin, Ahmad \\ Ainuddin $^{3}$., Bose, Mahmud Mohammad ${ }^{1}$, Binyehmed, Fadel Mohamed $^{1}$., Ben \\ Youssef, Khaleed Ali Ahmed ${ }^{1}$., Gabriel Emmanuel ${ }^{4}$. \\ ${ }^{I}$ Air Pollution \&Ecophysiology Laboratory, Faculty of Environmental Studies, Universiti Putra Malaysia, \\ 43400 UPM Serdang, Selangor, Malaysia. \\ ${ }^{2}$ Environmental Forensics Research Centre, Faculty of Environmental Studies, Faculty of Environmental \\ Studies, Universiti Putra Malaysia, 43400 UPM Serdang, Selangor DarulEhsan, Malaysia. \\ ${ }^{3}$ Institute of Tropical Forest and Forest Product University Putra Malaysia 43400 UPM, Serdang, Selangor \\ DarulEhsan, Malaysia. \\ ${ }^{4}$ Department of Urban and Regional Planning, School of Environmental Technology, Federal University of \\ Technology, Akure Nigeria
}

Corresponding author: Ahmad Makmom Abdullah, Environmental Forensics Research Centre, Faculty of Environmental Studies, Universiti Putra Malaysia, 43400 UPM Serdang Selangor, Malaysia. amakmom@upm.edu.my Office: +60389466733. Mobile phone: +60196183743, Fax 03-89438109

\begin{abstract}
This study was conducted to investigate the rate of soil respiration from a recovering forest of the tropics and its relationship with changes in environmental factorsafter years of deforestation. Soil respiration measurement was conducted using the continuous open flow chamber technique connected to a multi gashandling unit and infrared gas analyser, while the forest biomass and soil properties were quantified using the Kjeldahl method and Walkley-black wet oxidation technique. The average means soil respiration rate were 341.23, 383.07, 340.30, 308.12, 286.07, $256.05 \mathrm{mg} \mathrm{m}^{-2} \mathrm{~h}^{-1}$ between June and December. Soil respiration in the month of July was significantly $(p<0.01)$ higher compare to other months, with lower emission rate in December. Soil respiration exhibited a variation pattern that was similar to soil temperature pattern, the pattern varied monthly. Likewise, the forest carbon input and soil properties were found to be significantly correlated with soil respiration as they provide nutrients for microorganism to emit soil $\mathrm{CO}_{2}$. The remarkable soil $\mathrm{CO}_{2}$ emission from the recovering forest was attributed to changes in environmental factors as the forest is recovering from deforestation. The correlation and multiple linear regression model proved that environmental factors influenced the high rate of soil $\mathrm{CO}_{2}$ emission indicating a strong positive relationship $(0.94 ; p<0.01)$. These results suggestthat forest recovering could still emit considerable percentages of soil $\mathrm{CO}_{2}$ due to the impact from deforestation which could have a great implication on environmental factors and the atmospheric carbon balance.
\end{abstract}

Keywords:Forest biomass; Recovering forest; Soil carbon stock; Soil respiration; soil temperature

\section{Introduction}

Global concerns over increasing atmospheric carbon dioxide concentrations and its possible effects on the climate change have prompted worldwide extensive research on soil respiration [1]. Thison-going global climate change situation has directly and dramatically altered the terrestrial ecosystem processes, as a result of changes in greenhouse gases, water and transfer rate of energy at the planetary surface[2,3]. While the forests play an important role in the global carbon balance as the carbon fixed by the forests accounts for $80 \%$ and the soil accounts for $40 \%$ [4]. Carbon sequestration in the forest ecosystems is as results from the difference between photosynthetic carbon fixation and ecosystem respiration [5]. As it has been reported[6] that ecosystem respiration is responsible for the net ecosystem carbon exchange, and recovering forest results from deforestation, therefore, they are found to have great implication on the atmospheric carbon pool [7] as it emits considerable percentage of $\mathrm{CO}_{2}$ to the atmosphere compare to the undisturbed forest [8,9]. Therefore, estimating the contribution of soil respiration into the atmosphere from a recovering forest is important in global carbon cycle and climate change.

Soil respiration in the forest is an important process that determines the carbon loss from terrestrial ecosystem as it hosts the greater percentage of the ecosystem respiration[10,11]. Soil respiration has been recently accepted as a key element for evaluating the capacity of the forest ecosystems as a major component of the global carbon budget and its influence on climate change [12]. The huge spatial and temporal variation in soil respiration is mainly corresponding to intensive forests management resulting to changes in environmental 
factors and soil characteristics, [13]. Soil respiration and carbon cycles is one of the forest component dynamics that responds sensitively through forest management activities, fire and distribution of stand age, [14, [15,16], and these activities could greatly increasing or decreasing forest soil respiration depending on the forest ecosystems [17,18]. In addition, the ecophysiological characteristics of forest and forest productivity is influenced by human activities to altered the stand density [19] and in turn the stand density affects soil moisture, nutritional availability in minerals soils and soil temperature, [20,21, 14].

Although many research works have been conducted to examine soil respiration, vegetation types, soil carbon pools and forest age under different climatic conditions [22,23,5] but limited information has been unveiled on the soil respiration and the recovering forests inclusive other environmental factors of the tropical forest ecosystem. Therefore, studies investigating the effects of recovering forest stand density on soil respiration in the tropical climate could provide important information for forest carbon management in the Southeast Asia. Malaysia forests ecosystem is under intense threat of deforestation, logging and land conversion and with pocket of afforestation and it is important to ascertain the amount of soil $\mathrm{CO}_{2}$ emitting from this recovering forest and its implication on the atmospheric carbon balance as few studies have been conducted. The objectives of this study were(1) toinvestigate the rate of soil respiration from a recovering forest and (2) to examine the relationship between soil respiration and environmental factors under recovering forest of the tropics.

\subsection{Study site}

\section{Materials And Methods}

This study was conducted in a 15 years old recovering forest, located in the lowland Peninsular Malaysia $\left(27^{0} 41^{\prime} 33^{\prime \prime} \mathrm{N}, 43^{0} 60^{\prime} 74^{\prime \prime} \mathrm{E}\right)$. The experiment was carried out in a $1 \mathrm{x} 1$ ha plot with two replicates. The Dipterocarpusforesthad been regenerated and the stand density was naturally maintained without any artificial management such as thinning. There was little ground vegetation and its contribution to below ground biomass to total above ground biomass was negligible. The soil is dominated by a red colour derived from the alluvium colluvium resulting from metamorphic rock[24], with a mean temperature range of $23.7-32^{\circ} \mathrm{C}$ and relative humidity of 59-96\% and the tropical climate experiences pre-monsoon to monsoon period from September, November to January, respectively with a monthly rainfall of 200mm[25].

\subsection{Measurement of soil respiration}

Soil respiration was measured using two constructed continuous open flow chambers connected to a multi gas-handler (WA 161 model), which provides a channel to regulate the flow of $\mathrm{CO}_{2}$ from various chambers to a flow meter connected to a $\mathrm{CO}_{2} / \mathrm{H}_{2} \mathrm{O}$ gas analyser as descript by [7]. Thirty sampling points were established and soil collars were inserted $3 \mathrm{~cm}$ into the soil for 24 hoursto create an equilibrium stage before chambers were placed on them, with a $3 \mathrm{~cm}$ thick closed foam gasket to prevent leakage from the chamber base. Soil $\mathrm{CO}_{2}$ efflux was measured continuously on a daily basis from 8:00 to 17:00 hours. Efflux was recorded every $5 \mathrm{sec}$ over a period of $5 \mathrm{~min}$ in each chamber, from which an average was calculated to estimate the $\mathrm{CO}_{2}$ concentration over $5 \mathrm{~min}$ for each chamber.

During the measurement of soil respiration,soil temperature, soil moisture and water potential were measured concurrently usingthe soil temperature probes, moisture probes andTrime-FM TDR (Watchdog data logger model 125 spectrum technology, Delmorst model KS-D1 and Trime-Fm TDR, respectively) at 5m.

\subsection{Litterfall input, leaf area index (LAI) and forest biomass}

To estimate the carbon input from forest biomass, tree height and diameter breast height (DBH) using DBH tape, $1.3 \mathrm{~m}$ above the forest floor within the study plot were measured [26] and the data generated were used for the calculation of Total Above Ground Biomass (TAGB), Below Ground Biomass (BGB), using [27], Total Forest Carbon (SOCs) using [28] model and Soil Organic Carbon Stock (SOCstock) based on [29] model. To estimate carbon to nitrogen ratio $(\mathrm{C} / \mathrm{N})$ and litter productivity, ten litter traps were installed at $1 \mathrm{~m}$ above the ground, litter fall was collected throughout the study period. The collected litter fall was separated into broadleaves, needles and miscellaneous parts, oven-dried at $75^{\circ} \mathrm{C}$ and weight. C:N ratio concentration by litterfall were determined by macro elemental analyzer (vario MACRO CN, ElementarAnalysensysteme GmbH, Germany). Leaf area index (LAI) was determined on a monthly basis during the period of the study using a sunfleckceptometer (AccuPAR model SF-80, Decagon, Pullman, WA). The sunfleckceptometer considers the canopy leaf distribution and LAI was calculated at an instant measurement by positioning the ceptometer horizontally $1 \mathrm{~m}$ aboveground level and 6 readings were taken at four cardinal directions within the stand density [30]. 


\section{Statistical Analysis}

A one-way analysis of variance (ANOVA) was used to compare the means difference and standard deviationof soil $\mathrm{CO}_{2}$ efflux, environmental factors and forest biomass in the recovering forests. This was followed by a post hoc Dunn's test and Tukey's honestly significant difference (HSD) test [7, 31]. Pearson correlation was calculated to determine the relationship between environmental factors, soil properties and soil $\mathrm{CO}_{2}$ efflux related to recovering forest, likewise, descriptive statistics was employed to explain the normality of data distribution and the multiple linear regression model was established to ascertain impact of environmental factors on soil $\mathrm{CO}_{2}$ efflux. The statisticalcalculations wereperformed using the SPSS software version 21.0 (SPSS Inc., Chicago, Illinois, USA).

\section{Results And Discussion}

\subsection{Monthly pattern of soil respiration rate and effects of Environmental Factors as a result of forest} recovering from deforestation

The total soil respiration varied obviously at different months in the recovering forest. Analysis of variance indicated that climatic condition and environmental factors of the recovering forest significantly affected soil respiration. There were significant differences of soil respiration of the entire measurement period between June and December $(\mathrm{p}<0.01)$, (Table 1). The average means soil respiration were 341.23, 383.07, 340.30, 308.12, 286.07, 256.05 $\mathrm{mg} \mathrm{m}^{-2} \mathrm{~h}^{-1}$, between June and December, respectively (Table 1), indicating soil respiration in the month of July to be significantly $(\mathrm{p}<0.01)$ higher compare to other months, with lower emission rate in December. On the aspect of environmental factors, daily and monthly soil temperature varied throughout the study period, the minimum value was record in the morning hours of about $24.99^{\circ} \mathrm{Cand}$ maximum value occurred in the afternoon at $25.98^{\circ} \mathrm{C}$. The highest soil temperature occurred between July and June, and the minimum occurred between August and December. Soil moisture was found to occurred at a ranged of 20.22 to $25.43 \%$ between June and December, which showed typical season pattern for the tropical area, with the peak occurring from September to December.

Soil respiration showed a similar pattern with soil temperature, the mean daily soil respiration rate was high in June and increased sharply with increasing soil temperature and low soil moisture. Soil respiration subsequently decreased into August and December with increased in soil moisture, indicating the magnitude of the monthly fluctuation was greater in July, followed by June while August to December showed much smaller fluctuations.

The soil respiration trend for the recovering forest during the study period shows the effects of environmental factors on monthly soil respiration rate. Correlation analysis showed that soil respiration was more strongly correlated with soil temperature $\left(R^{2}=0.82\right.$ to $\left.0.94 ; p<0.01\right)$ than soil moisture $\left(R^{2}=0.78\right.$ to 0.87 ; $\mathrm{p}<0.01)$ for the period of the study. A significant positive correlation was between soil temperature and soil moisture at the six different months was found $\left(\mathrm{R}^{2}=0.85 ; \mathrm{p}<0.01\right)$. This suggests that the effects of soil temperature and soil moisture are therefore confounded. To further clarify the effects of forest recovering resulting from deforestation on environmental factors and their influence to changes in soil respiration rate, partial correlation analysis was performed. With soil respiration as the control variable, the correlation between soil temperature and soil respiration was strongly positively significant $(0.579 ; \mathrm{p}<0.01)$. However, with soil moisture as the control variable, the correlation between soil moisture and soil respiration was moderate and significant $(0.421 ; \mathrm{p}<0.01)$, this was observed in the field as soil temperatures exert a stronger control than soil moisture during the dry season while in the growing season soil moisture plays a dominant role compare to soil temperature.

Soil respiration varied significantly during the period of study and the rate of fluctuations was in response to changes in environmental factors and soil properties due to forest recovering from deforestation activity. The average soil respiration obtained ranges from 113.77 to $536.00 \mathrm{mg} \mathrm{m}^{-2} \mathrm{~h}^{-1}$ similar to the study conducted in tropical lowland forest of Malaysia [7]. The instantaneous increase in soil respiration, as it attends its peak between June and July, the ending of the post monsoon, with an efflux average mean of 341.23 and $383.07 \mathrm{mg} \mathrm{m}^{-2} \mathrm{~h}^{-1}$, respectively, higher than the soil respiration in the tropical forest of Central Hokkaido, Japan [32], due to forest age different and attributed to the influenced of environmental factors from the recovering forest due to deforestation [33]. There wasa steady decrease in efflux rate between August and November at an average mean of $340.30,308.12,286.07$ and $256.05 \mathrm{mg} \mathrm{m}^{-2} \mathrm{~h}^{-1}$, respectively, much lower than Pasoh forest reserve lowland Peninsular [34,35], which was strongly influenced by the availability of soil moisture and was significant correlated $(\mathrm{p}<0.05)$. Our finding revealed that monthly variation in soil respiration was influenced by both soil temperature and moisture as was also reported by [36].The rise and decrease in soil respiration for the period of measurement was recorded to be parallel to soil temperature and soil moisture which indicated soil respiration had positively and significantly correlation with both soil temperature and moisture $(\mathrm{p}<0.05)$. Furthermore, it indicated that soil respiration and environmental factors interaction explained the spatial and temporal variation of soil respiration [10]. Previous research also attributed that there is a strong 
relationship between soil respiration and soil temperature and soil moisture as deforestation area and forest age greatly influence these environmental factors to emit $\mathrm{CO}_{2}$ [37].

In this study, the increase in soil respiration was attributed to the change in environmental factors as was observed to be one of the important controlling factors as it was influenced by deforestation activity on the recovering forest [38]. The soil temperature within the period of the study ranged between 24.99 and $25.98^{\circ} \mathrm{C}$, similar to the study conducted by [34], which stands to alter changes in environmental variables, likewise, soil moisture occurred at a ranged between 20.22 and $25.43 \%$.Furthermore, forest recovering from deforestation could influence the entire environmental factors, which explains the role of deforestation and less dense forest canopy cover as it increases the net radiation on the forest floor to provide a condition to necessitate microorganisms to facilitate soil respiration $[33,37]$.

\subsection{Forest biomass and soil properties contribution to soil respiration}

The recovering forest was found to hosts an estimated TAGB, BGB, SOCs and $\mathrm{SOC}_{\text {stock }}$ of $1.8 \times 10^{3}$, $1.0 \times 10^{3}, 2.4 \times 10^{3} \mathrm{mg}$ and $52.28 \mathrm{mg} \mathrm{ha}^{-1}$ respectively, the occurrences of these forest biomass increase the soil properties as nutrient for microbial activity.

To ascertain the contribution of soil properties, we analysed for total organic carbon (TOC), soil organic carbon $(\mathrm{SOC})$, soil $\mathrm{pH}$, carbon and nitrogen $(\mathrm{C} / \mathrm{N})$ and bulk density $(\mathrm{BD})$. The result revealed a considerable amount of $2.12 \%, 3.65 \%$ and $34.24-48.55 / 1.16-1.35 \%$ for TOC, SOC and C/N respectively, as these are responsible for increase in soil nutrient and the rate of organic matter decomposition. The resulted contribution by these soil properties are as result of influence of changes in environmental factors. The soil in the study area was found to be slightly acidic suitable for microbial activity. Generally, the multiple linear regression coefficients for each of the forest biomass and soil properties variables reflect a strong relationship between changes in environmental factors and their influence on soil respiration $\left(R^{2}=0.6 ; p<0.05\right)$.

The contribution of forest biomass and soil properties to soil nutrient, influences the total soil respiration which varies with vegetation type, soil type and environmental condition [39]. The recorded input from TAGB, BGB and SOCs were found to be considerable and similar the observed result from the tropical forest conducted by[33], likewise the $\mathrm{C} / \mathrm{N}$ ratio occurred at 34.24-48.55/1.16-1.35\% to increase the rate of decomposition. The considerable amount of these forest biomass and $\mathrm{C} / \mathrm{N}$ in the recovering forest are found to influenced the rate of soil carbon stock (SOCstock) by $52.28 \mathrm{mg} \mathrm{ha}^{-1}$ and soil properties, similar to the tropical forest of India [40] and lowland tropical forest of Malaysia [34], respectively. This result confirmed the significant role played by the forest biomass and $\mathrm{C} / \mathrm{N}$ ratio to increase soil nutrient for microorganism to emit soil $\mathrm{CO}_{2}$ as was also reported by [22] and [41].

\section{Conclusion}

This study demonstrated that soil respiration vary significantly as a function of environmental factors. Soil respiration of the young recovering forest was remarkably higher than that of the older forest of the tropical forest as a result of higher soil temperature, low soil moisture and forest biomass. Changes in environmental factors were as a result of deforestation impact which the recovering forest has less dense canopy cover to increase net radiation on the forest floor, thereby influencing soil temperature, whichresulted to high physiological activity of microorganism and fine roots which lead to more soil $\mathrm{CO}_{2}$ emissions. The results suggested that soil temperature was the dominant factor influencingsoil respiration $(0.94 ; \mathrm{p}<0.01)$ and subsequently followed by soil moisture. Forest biomass and soil properties input are combined interactive factors which increase soil nutrient and positively correlated with soil respiration at $R^{2}=0.6 ; p<0.05$, this indicated that soil respiration from microorganism is a function of soil nutrient. This result indicated that forest recovering from deforestation activity could emit considerable percentage of $\mathrm{CO}_{2}$ into the atmosphere, an implication for global climate change.

\section{Acknowledgements}

This research was jointly supported by the National Institute of Environmental Studies, Japan, and the Research Management Centre Universiti Putra Malaysia Grant Scheme (Project No. 0302122070) and Putra Grant (GPIPS/2013/9399600). We wish to thank the staff of Negeri Sembilan Forest Department, staff of the Centre for Marine and Oceanographic Studies, Universiti Putra Malaysia, Port Dickson Centre for their support.

\section{References}

[1]. Chen, J., Luo, W. Li, D., Yu, J., She, Y. (2014). Comparison of soil respiration among three different subalpine ecosystems on eastern Tibetan Plateau, China," Soil Sci. Plant Nutr., vol. 60, no. 2: 231-241.

[2]. IPCC (2007). Climate change : the physical sciences basis. Contribution of working group I to the fourth assessment report of the intergovernmental panel on climate change. IPCC, Cambridge, United Kingdom and New York, NY, USA.

[3]. Karl, T., Trenberth, K. (2003). Modern global climate change. Science 302:1719-1723.

[4]. Dixon, R. K. (1994). Carbon pools and flux of global forest ecosystems. Science 263:185-190. 
[5]. Gong, Z., Ge, R., An, Q., Duan, X., You, Y., Huang, J. (1994). Soil respiration in poplar plantations in northern China at different forest ages," Plant Soil, vol. 360, no. 1-2: 109-122.

[6]. Valentini, R., Matteucci, G., Dolman ,A. J., Schulze, E. D., Rebmann, C., Moors, E. J., Granier, A., Gross, P., Jensen, N.O,, Pilegaard, K., Lindroth, A., Grelle, A., Bernhofer, C., Grünwald, T., Aubinet, M.,Ceulemans, R., Kowalski, A.,S., Vesala, T., et al. (2000). Respiration as the main determinant of european forest carbon balance. Nature 404: 861-865.

[7]. Mande, K. H., Ahmad, A. M., Ahmad, Z. A., Ahmad, A.N.( 2013). Soil carbon dioxide efflux and atmospheric impact in a 10-year-old dipterocarpus recovering lowland tropical forest, peninsular Malaysia. From source to solution. Proceedings of the IENFORCE 2013. Springer Publishing: Heidelberg, New York, 165-169,” pp. 165-169, 2013.

[8]. Toland, D.E., \& Zak, D.R. (1994). Seasonal patterns of soil respiration in intact and clear-cut northern hardwood forests. Canadian Journal of Forest Research 24: 1711-1716.

[9]. Brito, J. L., Trujillo, D., Morales, M., Soledad, G., Wieser, P. (2013). Acta Oecologica Soil moisture overshadows temperature control over soil $\mathrm{CO}_{2}$ efflux in a Pinus canariensis forest at treeline in Tenerife , Canary Islands," Acta Oecologica, vol. 48: 1-6.

[10]. Janssens, I. A., Lankreijer, H., Matteucci, G., et al. (2001). Productivity overshadows temperature in determining soil and ecosystem respiration across European forests. Global Change Biology 7:269 - 278.

[11]. Raich, J. W., Potter, C. S., \& Bhagawati, D. (2002). Interannual variability in global soil respiration, 1980-94. Global Change Biology, 8, $800-812$.

[12]. Wang, C. K., Yang, J. Y., Zhang, Q. Z. (2006). Soil respiration in the six temperate forest in China. Globe change Biol. 12, $2103-2114$.

[13]. Gough, C. M., Seiler, J, R. (204). The influence of environmental, soil carbon, root and stand characteristics on soil CO2 efflux in loblolly pine (Pinus taeda L.) plantations located on the South Carolina Coastal Plain. For Ecol Manag 191:353 - 363.

[14]. Tang J, Qi Y, Xu M, Misson, L.G.A. (2005). Forest thinning and soil respiration in a ponderosa pine plantation in the Sierra Nevada. Tree Physiol 25:57-66.

[15]. Yan, J., Wang, Y., Zhou, G., Zhang, D (2006). Estimates of soil respiration and net primary production of three forests at different succession stages in south China. Globe Change Biol 12:810 - 821," pp. 810 - 821, 2006.

[16]. Kim, C., Son, Y., Lee, W.K., Jeong, J., Noh, N.J. (2009). Influences of forest tending works on carbon distribution and cycling in a Pinus densiflora S. et Z. stand in Korea. For Ecol Manag 257:1420 - 1426,” pp. 1420 - 1426, 2009.

[17]. Ohashi, M., Gyokusen, K., Saito, A. (1999).“Measurement of carbon dioxide evolution from a Japanese cedar (Cryptomeria japonica D. Don) forest floor using and open-flow chamber method. For Ecol Manag 256:201 - 208," pp. 201 - 208, 1999.

[18]. Kim, C., Son, Y., Lee, W.K., Jeong, J., Noh, N. J. (2009). Influences of forest tending works on carbon distribution and cycling in a pinusdensiflora s.et. z stand in Korea. For. Ecol. Manage. $257: 1420-1426$.

[19]. Litton, C. M., Ryan, M. G., Knigh, D. H., Stahl, P. (2003). Soil surface carbon dioxide efflux and microbial biomass in related to tree density 13years after a stand replacing fire in a lodge pole pine ecosystem. Global change Biol. 9,680-696.

[20]. Litton, C.M., Ryan, M.G., Knight, D.H. (2004). Effects of tree density and stand age on carbon allocation patterns in postfire lodgepolepine. Ecol Appl 14:460 - 475.

[21]. Son, Y., Jun, Y.C., Lee, Y.Y., Kim, R.H., Yang, S.Y. (2004). Soil carbon dioxide evolution, litter decomposition, and nitrogen availability four years after thinning a Japanese larch plantation. Commun Soil Sci Plant Anal 35:111 - 1122.

[22]. Hibbard, K. A., Law, B. E., Reichstein, M., Sulzman, J. (2005). An analysis of soil respiration across northern hemisphere temperate ecosystems. Biogeochemistry. 73, 29-70.

[23]. Davidson, E. A., Janssens, I. A. (2006). Temperature sensitivity of soil carbon decomposition and feedbacks to climate change. Nature. 440, $165-173$.

[24]. Paramananthan S. (2012). Keys to the Identification of Malaysian Soils using Parent Materials, 2-20,” no. M, pp. 2-20.

[25]. Suhaila and A. A. Jemain, J. (2008). Fitting the Statistical Distribution for Daily Rainfall in Peninsular Malaysia Based on AIC Criterion," vol. 4, no. 12 , pp. 1846-1857.

[26]. Manokaran, N., LaFrankie, J. V., Kochummen, K. M., Quah, E. S., Klahn, J. E., Ashton, P. S., and Hubbell, S.P. (1990). Methodology for the fifty-hectare research plot at Pasoh Forest reserve, Res. Pam. For. Res. Inst. Malaysia 104, 1 - 69.

[27]. Kato, J., Tadaki, Y., Ogawa, H. (1978). Biomass and growth increment studies in Pasoh Forest, Malaysia. Nat. J. 30, 211-224.

[28]. Ogawa, J. M., Sandeno, J. L., and Mathre, J. H. (1963). Comparisons in development and chemical control of decay organism on mechanical and hand harvested stone fruits. Plant Das. Rep 47. 129- 133.

[29]. Eleanor, M. (2008). Soil organic carbon. In: Cleveland CJ (ed) Encyclopedia of earth. Environmental Information Coalition, National Council for Science and the Environment, Washington, DC. Retrieved June 13, 2009. <http://www.eoearth.org/article/Soil_organ.

[30]. Bolstad, P.V., Gower, S. T. (1990). Estimation of leaf area index in fourteen southern Wisconsin forest stands using a potable radiometer. Tree Physiol 7:115-124.

[31]. Müller, N. Rottmann, A. Bergstermann, H. Wildhagen, and R. G. Joergensen, E. (2011). Soil $\mathrm{CO}_{2}$ evolution rates in the field - a comparison of three methods," Arch. Agron. Soil Sci., vol. 57, no. 6: 597-608.

[32]. Taylor P, Hu, R. (2011). Soil Respiration and Net Ecosystem Production in an Onion Field in Central Hokkaido, Japan, Soil science and plant nutrition, $37-41$.

[33]. Mande, K. H., Abdullah, A. M., Zaharin, A.A., \& Ainuddin, A.N. (2014). "Drivers of Soil Carbon Dioxide Efflux in a 70 years Mixed Trees Species of Tropical Lowland Forest, Peninsular Malaysia," vol. 43, no. 12: 1843-1853.

[34]. Mande, K.H., Abdullah, A.M., Aris, .Z., \&Ainuddin, A.N. (2014). Factors responsible for spatial and temporal variation of soil CO2 efflux in a 50 year recovering tropical forest, Peninsular Malaysia," Environ. Earth Sci., pp. DOI 10.10077/s12665-014-3810-8, Oct. 2014.

[35]. Adachi, M., Bekku, Y., Rashidah, W., Okuda, T., \&Koizumi, H. (2006). Differences in soil respiration between different tropical ecosystems," Appl. Soil Ecol., vol. 34, (2-3): 258-265.

[36]. Shi, Z., Li, Y.Q., Wang, S.J., Wang, G. B., Ruan, H. H., He, R., Tang, Y. F., Zhang, Z. X. (2009). Accelerated soil CO 2 efflux after conversion from secondary oak forest to pine plantation in southeastern China. Ecol Res 24:1257 - 1265.

[37]. McCarthy, D. R., Brown, K. J. (2006). Soil respiration responses to topography, canopy cover, and prescribed burning in an oakhickory forest in southeastern Ohio. For Ecol Manage 237:94 - 102.

[38]. Davidson, E. A., Belk, E., Boone, R. D.(1998). Soil water content and temperature as independent of confounded factors controlling soil respiration in a temperate mixed hardwood forest. Glob Chang Biol 4:217 - 227.

[39]. Bond-Lamberty, B., Wang, C., Gower, S. T. (2004). Global relationship between the heterotrophic and autotrophic components of soil respiration? Global Change Biol 10:1756 - 1766.

[40]. Ravindranath, N. H., Somasekhar, B. S., Gadgil, M. (1997). Carbon flows in Indian forest. Climate Change 35:297-320.

[41]. Jandl, R., Lindner, M., Vesterdal, L., Bauwens, B., Baritz, R., Hagedorn, F., Johnson, D. W., Minkkinen, K., Byrne, K. A. (2007). How strongly can forest management influence soil carbon sequestration? Geoderma 137:253 - 268. 
Table 1 Descriptive statistics of mean different of soil respiration rate $\left(\left(\mathrm{mg} \mathrm{m}^{-2} \mathrm{~h}^{-1}\right)\right.$

\begin{tabular}{|c|c|c|c|c|c|c|c|c|}
\hline & \multirow[t]{2}{*}{$\mathrm{N}$} & \multirow[t]{2}{*}{ Mean } & \multirow[t]{2}{*}{$\begin{array}{l}\text { Std. } \\
\text { Deviation }\end{array}$} & \multirow[t]{2}{*}{ Std. Error } & \multicolumn{2}{|c|}{$\begin{array}{l}95 \% \text { Confidence Interval for } \\
\text { Mean }\end{array}$} & \multirow[t]{2}{*}{ Minimum } & \multirow[t]{2}{*}{ Maximum } \\
\hline & & & & & Lower Bound & Upper Bound & & \\
\hline June $\mathrm{CO} 2$ efflux & 72 & 341.23 & 98.13 & 11.56 & 318.17 & 364.29 & 140.55 & 488.23 \\
\hline July $\mathrm{CO} 2$ efflux & 72 & 383.07 & 91.20 & 10.75 & 361.64 & 404.50 & 228.22 & 536.00 \\
\hline August $\mathrm{CO} 2$ efflux & 68 & 340.30 & 67.05 & 8.13 & 324.06 & 356.53 & 201.38 & 446.33 \\
\hline SeptCO2 efflux & 72 & 308.12 & 103.18 & 12.16 & 283.87 & 332.36 & 115.33 & 458.22 \\
\hline Oct $\mathrm{CO} 2$ efflux & 72 & 286.07 & 73.81 & 8.70 & 268.73 & 303.42 & 149.00 & 400.33 \\
\hline Nov CO2 efflux & 72 & 256.05 & 70.54 & 8.31 & 239.47 & 272.62 & 113.77 & 353.00 \\
\hline Total & 428 & 318.94 & 94.40 & 4.56 & 309.97 & 327.91 & 113.77 & 536.00 \\
\hline
\end{tabular}

